\title{
Editorial for the Special Issue on Optofluidic Devices and Applications
}

\author{
Francisco Yubero ${ }^{1, *(1)}$ and Fernando Lahoz ${ }^{2, *}$ \\ 1 Instituto de Ciencia de Materiales de Sevilla (CSIC-University Sevilla), 41092 Sevilla, Spain \\ 2 Departamento de Física, IUdEA, Universidad de La Laguna, 38200 Santa Cruz de Tenerife, Spain \\ * Correspondence: yubero@icmse.csic.es (F.Y.); flahoz@ull.es (F.L.)
}

Received: 9 September 2020; Accepted: 20 September 2020; Published: 23 September 2020

Optofluidic devices are of high scientific and industrial interest in chemistry, biology, material science, pharmacy, and medicine. In recent years, they have experienced a strong development because of impressive achievements in the synergistic combination of photonics and micro- and nano-fluidics. Thus, sensing and/or lasing platforms showing unprecedented sensitivities in extremely small analyte volumes, and allowing real-time analysis within a lab-on-a-chip approach, have been developed. They are based on the interaction of fluids with evanescent waves induced at the surface of metallic or photonic structures, on the implementation of microcavities to induce optical resonances in the fluid medium or on other interactions of the microfluidic systems with light. In this context, a large variety of optofluidic devices have emerged, covering topics such as cells manipulation, microfabrication, water purification, energy production, catalytic reactions, microparticle sorting, micro-imaging, or bio-sensing. Moreover, integration of these optofluidic devices in larger electro-optic platforms represents a highly valuable improvement towards advanced applications, such as those based on surface plasmon resonances, already in the market.

In this Special Issue on Optofluidic Devices and Applications, we include 10 papers, covering different aspects related to water quality monitoring (1) and purification (4), structural stability of nanohole array-based devices (2), hydrodynamical focusing (3), fluorescence-based thermometry (5), electrofluidics (6), electrowetting (7) and optofluidic manipulation (8). Additionally, there are two interesting review papers on opto-electrokinetic-based manipulation and fabrication (9) and portable optofluidic systems for ocean monitoring (10).

In particular, Zuo et al. describe an optofluidic device for precise real-time detection of dissolved oxygen based on the plasmon resonant shift of silver nanoprisms with potential application in biomedical or water sensing fields [1]. Bdour et al. present an investigation of the deflection and structural stability of nanohole array-based optofluidic sensors operating in flow-through mode [2]. Hamilton et al. describe a study where 3D hydrodynamic focusing was implemented in $10 \mu \mathrm{m}$ scale microchannel cross-sections made with a single sacrificial layer, which, implemented in optofluidic sensors, enable higher detection sensitivity and sample specificity [3]. Li et al. report a paper-based photocatalyst immobilization method with enhanced purification efficiency that solves the so-called "coffee ring effect" that occurs on the substrate during solvent evaporation, resulting in the aggregation of the photocatalysts [4]. Ghifari et al. describe a proof of concept of an optofluidic method based on dye-doped $\mathrm{ZnO}$ microcapsules for high throughput fluorescence-based thermometry, which enables the measure of temperature inside optofluidic microsystems at the millisecond time scale [5]. Deng et al. report on two kinds of electro-fluidic dyes based on anthraquinone and azo pyrazolone, including their synthesis, structure characterization, and application properties [6]. Yi et al. present a study related to the aperture ratio improvement by optimizing the voltage driving waveform for electrowetting displays [7]. Winskas et al. demonstrate a new bi-metallic substrate that allows micro-scale optofluidic manipulation controlled by an external laser power [8]. Liang et al. present a variety of differently 
structured optoelectrokinetic chips, discussing how they are fabricated and the ways in which they work. They also provide a summary of the current challenges of optoelectrokinetics and their future prospects [9]. Finally, Wang et al. describe the applications of optofluidic platforms on autonomous and in situ ocean environmental monitoring, with an emphasis on their principles, sensing properties, advantages, and disadvantages [10].

Funding: We thank the AEI-MICINN and EU-FEDER (PID2019-110430GB-C21 and PID2019-107335RA-I00) for financial support.

Acknowledgments: We would like to take this opportunity to thank all the authors for submitting their papers to this Special Issue, all the reviewers for dedicating their time and helping to improve the quality of the submitted papers, and our assistant editor Mandy Zhang for her kind invitation and support for the production of this Special Issue.

Conflicts of Interest: The authors declare no conflict of interest.

\section{References}

1. Winskas, J.; Wang, H.; Zhdanov, A.; Cheemalapati, S.; Deonarine, A.; Westerheide, S.; Pyayt, A. Different Regimes of Opto-fluidics for Biological Manipulation. Micromachines 2019, 10, 802. [CrossRef]

2. Yi, Z.; Feng, W.; Wang, L.; Liu, L.; Lin, Y.; He, W.; Shui, L.; Zhang, C.; Zhang, Z.; Zhou, G. Aperture Ratio Improvement by Optimizing the Voltage Slope and Reverse Pulse in the Driving Waveform for Electrowetting Displays. Micromachines 2019, 10, 862. [CrossRef] [PubMed]

3. Wang, F.; Zhu, J.; Chen, L.; Zuo, Y.; Hu, X.; Yang, Y. Autonomous and In Situ Ocean Environmental Monitoring on Optofluidic Platform. Micromachines 2020, 11, 69. [CrossRef] [PubMed]

4. Liang, W.; Liu, L.; Wang, J.; Yang, X.; Wang, Y.; Li, W.; Yang, W. A Review on Optoelectrokinetics-Based Manipulation and Fabrication of Micro/Nanomaterials. Micromachines 2020, 11, 78. [CrossRef] [PubMed]

5. Deng, Y.; Li, S.; Ye, D.; Jiang, H.; Tang, B.; Zhou, G. Synthesis and a Photo-Stability Study of Organic Dyes for Electro-Fluidic Display. Micromachines 2020, 11, 81. [CrossRef]

6. Ghifari, N.; Rassouk, S.; Hayat, Z.; Taleb, A.; Chahboun, A.; El Abed, A. Dye-Doped ZnO Microcapsules for High Throughput and Sensitive Optofluidic Micro-Thermometry. Micromachines 2020, 11, 100. [CrossRef] [PubMed]

7. Li, Q.; Lin, H.; Huang, X.; Lyu, M.; Zhang, H.; Zhang, X.; Wang, R. Paper-based Photocatalysts Immobilization without Coffee Ring Effect for Photocatalytic Water Purification. Micromachines 2020, 11, 244. [CrossRef] [PubMed]

8. Hamilton, E.; Ganjalizadeh, V.; Wright, J.; Schmidt, H.; Hawkins, A. 3D Hydrodynamic Focusing in Microscale Optofluidic Channels Formed with a Single Sacrificial Layer. Micromachines 2020, 11, 349. [CrossRef] [PubMed]

9. Bdour, Y.; Gomez-Cruz, J.; Escobedo, C. Structural Stability of Optofluidic Nanostructures in Flow-Through Operation. Micromachines 2020, 11, 373. [CrossRef] [PubMed]

10. Zuo, Y.; Chen, L.; Hu, X.; Wang, F.; Yang, Y. Silver Nanoprism Enhanced Colorimetry for Precise Detection of Dissolved Oxygen. Micromachines 2020, 11, 383. [CrossRef] [PubMed]

(C) 2020 by the authors. Licensee MDPI, Basel, Switzerland. This article is an open access article distributed under the terms and conditions of the Creative Commons Attribution (CC BY) license (http://creativecommons.org/licenses/by/4.0/). 